\title{
Movimentos sociais como tema de diferentes áreas de estudo
}

\begin{abstract}
Almir Del Prette
Professor do Departamento

de Psicologia da Universidado

federal da Paraíba.
\end{abstract}

$M$ compartimentalização do ensino em disciplinas, unidades, módulos, etc. tem promovido a percepção, especialmente do estudante, de que as áreas de comunicação são demarcadas por fronteiras que delimitam uma práxis única, facilmente reconhecível e inteiramente inconfundivel. Algumas vezes essa percepção acompanha também o pesquisador dificultanto a própria compreensão do objeto sob sua investigação. O conjunto de teorias de cada área apresenta diferentes pontos de vista sobre aspectos de um mesmo objeto e, assim, fornece elementos de originalidade e especificidades próprios. Apesar disso, a originalidade e especificidade que delimitam pontos fronteiriços entre áreas, sob certos aspectos, não se sustentam como auto-suficientes, em termos de modelos amplos que dispensem o concurso advindo de áreas afins.

$\mathrm{O}$ intercâmbio entre as ciências $\dot{e}$, ao que parece, uma realidade que pode ser observada no desenvolvimento conjunto de projetos de pesquisa, na utilização de categorias de análise por diferentes áreas, no múltiplo aproveitamento de dados, na troca de tecnologia, etc, buscando-se um maior reconhecimento e dominio sobre um objeto de estudo e modelos explicativos mais abrangentes. $O$ desenvolvimento desse intercâmbio possibilita a interação entre áreas de conhecimento, derivando novas abordagens como, por exemplo, Psicologia Fisiológica, Marxista; Antropologia Psicológica, etc.

Investigaçōes no âmbito da Psicologia, Antropologia e Sociologia, para citar apenas algumas, reafirmam uma espécie de "solidariedade" necessária ao aprofundamento de seus estudos e abrem perspectivas ao desenvol- vimento de métodos e técnicas de pesquisa e de ampliação de novos campos de investigação.

Um objeto de estudo que ilustra a necessidade e a relevância da integração entre algumas áreas do conhecimento é o estudo de grupos e movimentos sociais. Embora com longa tradição de pesquisa sobre grupo, a visão da Psicologia americana tem sido a de tomá-lo como comportamento entre indivíduos. Essa abordagem, ao que parece, tem desencorajado o estudo do comportamento coletivo como movimentos sociais, no qual as questões grupais necessariamente se colocam. Essa lacuna enfraquece qualquer contribuição da Psicologia para outras ciências que estudam o tema e se articulam como é o caso da Antropologia e Sociología. Por outro lado, a Psicologia Social de tradição européia oferece uma perspectiva alternativa ao estudo do fenômeno grupal, a do comportamento intergrupal, que se contrapõe às teorias de base interpessoal no trato dessas questões. Essa tradição européia não tem recebido dos estudiosos do terceiro mundo, certamente por razões ligadas à "hegemonia do conhecimento americano" (que não será objeto de anátise no momento), á atençào necessária a sua divulgação.

A importância do estudo de grupos e movimentos sociais justifica apresentar alguns dos pressupostos da teoria do comportamento intergrupal, esperando despertar o interesse para o estudo da Psicologia Social de tradição européia e a pesquisa de tais temas cuja compreensão aponta para a possibilidade de integrar conhecimentos produzidos na Psicologia aos já existentes em outras áreas e, inversamente, promover o seu aprofundamentoa partir da contribuição das outras cièncias.

\section{O grupo social}

o comportamento humano, e particularmente o comportamento humano envolvido na formação e nas relações entre grupos sociais, tem sido objeto de interesse de um amplo espectro de áreas de investigação que, embora com maior ênfase nas ciências humanas, estende-se também, por razö̀s nem sempre óbvias de imediato, às áreas comumente denominadas de ciências biológicas ou fisicas bem como àquelas que, de alguma forma, representam pontos intermediários entre os dois primeiros e os dois últimos conjuntos.

Parece ser concordância geral a importância de se ampliar o conhecimento sobre o comportamento humano e, na medida em que a sociedade humana é basicamente estruturada em grupos ("ninguém é uma ilha"), o estudo do comportamento não pode prescindir da noção do pertencimento a diferentes grupos e, portanto, de uma compreensão cada vez maior sobre o fenomeno grupal.

A apreensăo da realidade de um grupo (pequeno ou grande) pode ser obtida através da análise da estrutura sócio-econômica, histórica ou política $e$, dependendo da área de investigação considerada, o conhecimento resultante apresentará as características e especificidades do nível de análise daquela área.

Tomando-se, por exemplo, a diferenciação da estrutura social em grupos e os conflitos daí derivados, as análises que levam em consideração os aspectos sócio-econômico-psicológicos respondem de maneira mais abrangente do que a ênfase em apenas um desses aspectos.

O estudo do fenômeno de grupo tem recebido muita atenção, embora o seu interesse venha decrescendo na Psicologia Social americâna (11). As 
"variáveis" denominadas coesão, atração, liderança, etc. têm sido exaustivamente estudadas como uma tentativa de especificação das "leis" de funcionamento grupal (2). Em geral esses estudos têm privilegiado a pesquisa com grupos pequenos enfatizando, quase sempre, o papel das relações interpessoais na formação, manutenção e atividade dos grupos sociais. Embora se possa considerar a importância desses estudos, as questôes igualmente importantes decorrentes das relações entre membros de categorias sociais amplas como nações, classes, religiões, etc. têm recebido muito pouca atenção dos estudiosos em Psicologia.

\section{Fillaçăo grupal}

A filiação e a participação em grupos são uma característica universal da vida em sociedade. $O$ individuo se filia a diferentes grupos sociais e esse seu "pertencimento" a tais grupos influencia grande parte das relaçōes a serem por ele desenvolvidas (17). $\mathrm{O}$ pertencer psicológico a um grupo apresenta características empiricas tidas como consensuais na Psicologia Social (16). A primeira característica é a perceptual, ou seja, algumas pessoas se definem e são por outras definidas como um grupo ao compartilhar uma percepção de si mesma como uma entidade socialmente distinta, o "nós" em oposição ao "eles"; a segunda é a interdependência, que reside no fato de os membros do grupo proverem, entre si, a satisfação de suas necessidades (10); e a terceira característica é a da estrutura social, um grupo apresenta interações entre indivíduos que são organizadas e reguladas por um sistema de regras, normas, valores e status diferenciados e compartilhados.

Poder-se-ia argumentar, no entanto, que essas características são apropriadas quando se trata de grupos pequenos, podendo não satisfazer inteiramente quando se considera grupos amplos, como por exemplo uma nação. E de fato, a exceção da perceptual, as demais não se configuram como condição presente na maioria dos grupos amplos.

Tomando-se o questionamento acima e aplicando-o ao caso brasileiro, em analogia à exemplificação de Turner e Giles (17), pode-se dizer que este (grupo-nação) nào forma um grupo emergente que tenha se iniciado com base em relações interpessoais, mas "aparece" como decorrência de uma realidade histórico-cultural. Nesse caso, tal categoria (o pertencimento ao grupo) é imposta, mesmo que não satisfaça as necessidades do individuo e que seus membros não atuem cooperativamente. Apesar dessas considerações, o brasileiro (como outra categoria análoga) forma um grupo social não apenas no aspecto geográfico-econômico e político, mas no sentido psicológico-social. Em muitos casos, sob certas circunstâncias, o brasileiro compartilha emoções comuns e age de forma relativamente semelhante. Exemplos mais representativos seriam as comemorações que assinalam a Independência do País e as disputas internacionais de futebol, envolvendo a seleção nacional.

Dessa forma, a definição de grupo, com base na teoria do comportamento intergrupal (12), que inclui tanto grupo amplos como pequenos, seria a de um conjunto de pessoas que se designam e são por outros designadas como um grupo. Essa definição parece bastante apropriada, tanto aos estudos de Psicologia Social quanto aos de outras áreas de pesquisa.(*) Tal defi-

Nesse sentido ver as definiçōes correntes de grupos relacionados'as principais correntes sociológicas e considerações sobre o tema, em: M.Horkheimer e T.W. Adorno (orgs) Temas básicos de sociologia. São Paulo Cultrix, 1973 (Cap. IV - O Grupo).

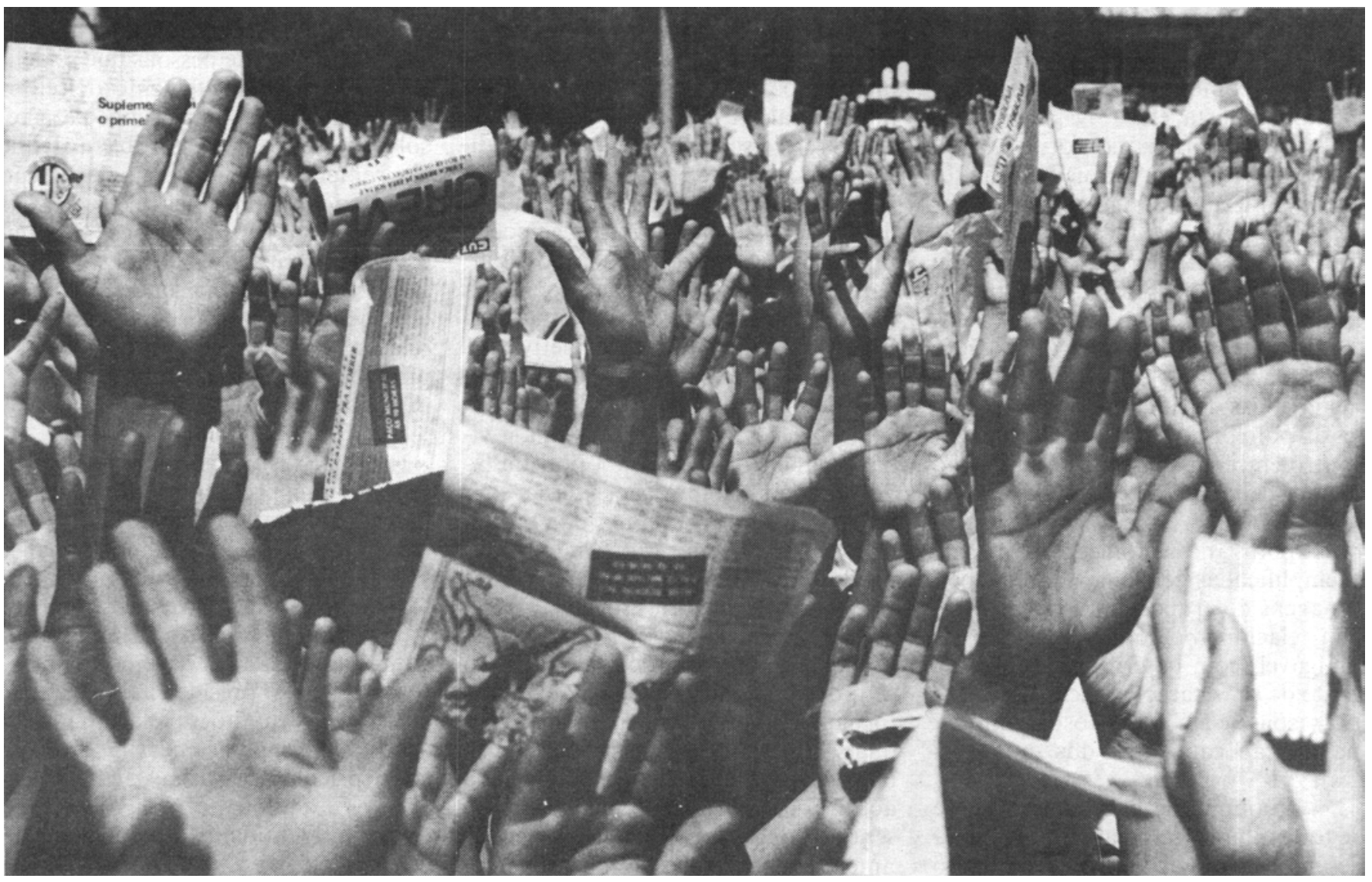

PSICOLOGIA CIENCIA E PROFISSAOO 37 
nição na base da característica perceptual apresenta três componentes: a) o cognitivo, identificado pela consciência de pertencer a um grupo; b) o avaliativo, que corresponde à valoração positiva ou negativa que se atribui a uma filiação qualquer; c) o emocional, que decorre da avaliação do próprio pertencer ao grupo.

A filiação a diferentes grupos sociais constitui a base para o desenvolvimento da identidade social do indivíduo. Esta Identidade relaciona-se com o conceito que a pessoa tem sobre si mesma e é derivada das suas filiações. $O$ individuo adquire a consciência de pertencer a um grupo e tende a diferenciá-lo dos demais, maximizando os seus aspectos positivos e classificando os outros segmentos sociais em termos valorativos. Quando a filiação a um grupo contribui negativamente para a sua identidade social pode ocorrer tentativas de abandonar o grupo e, na sua impossibilidade, $o$ indivíduo procura melhorar o próprio status grupal em relação a outras categorias sociais.

\section{A influencia da fillaçäo grupal}

E possivel pensar que os aspectos ligados a uma filiação particular influenciem o comportamento de uma pessoa em uma dada interação social. Por exemplo, a pessoa pode se comportar como pertencente à "Fiel corintiana", como estudante da universidade $\mathrm{X}$, como membro de um movimento feminista, etc.

Dessa forma, conforme Tajfel (12), as interações sociais podem ser vistas em termos de um contínuo, onde, em um pólo se localizam as relações puramente intergrupais e, em seu oposto, as interpessoais. $\mathrm{Na}$ primeira extremidade referida ocorreria o encontro entre pessoas cuja interação é exclusivamente determinada pelas características de cada um dos integrantes. $O$ pólo intergrupal refere-se ao encontro entre pessoas onde a interação é exclusivamente determinada pela filiação grupal. As oscilações entre os dois pólos da interação têm sido exemplificadas pelo cinema, onde personagens de grupos conflitantes mantêm relacionamento ora cordial e até amigável (com base na atração resultante de suas características pessoais), ora ríspido e até inamistoso (com base na filiação categórica dos interagentes).

A amplitude e a complexidade de toda interação social se movimenta de um extremo ao outro no contínuo (entre o pólo interpessoal e $o$ intergru38 PSICOLOGIA CIENCIA E PROFISSAO pal). Assim, quanto mais próxima for uma relação social do extremo interpessoal, maior tendência à variabilidade comportamental em relação aos membros de outros grupos, e quanto maior a proximidade ao extremo intergrupal haverá uma tendência a uma maior uniformidade comportamental. Crencas e normas

Uma Psicologia Social voltada para o estudo do comportamento coletivo e de grupo, deve, necessariamente, levar em consideração a heterogeneidade do ambiente social, onde as pessoas se diferenciam ao pertencerem a diferentes grupos. Os grupos, além de desenvolverem uma subcultura própria nas suas relaçōes, desenvolvem ou mantêm em seus membros um sistema de crenças e normas. $O$ sistema de crenças explica para o indivíduo grande parte dos fenômenos do mundo físico e social e atua igualmente como determinante importante do comportamento. As crenças são desenvolvidas e mantidas no complexo das relações sociais, podendo servir como base para o controle de um grupo sobre o outro, para a dominação do Estado sobre indivíduos e grupos, mas também de reações a tais controles.

A estrutura de crenças sobre, por exemplo, a flexibilidade ou rigidez da estratificação social parece determinar, em parte, a natureza das relações entre os membros de diferentes grupos, se se faz a partir de -uma base interpessoal ou a partir de uma base intergrupal. A crença na mobilidade social refere-se à percepção que $o$ individuo tem de que ele pode melhorar a sua posição através da ação individual. A crença na estratificação social representa a percepção na impossibilidade de mudança de posição ocupada na sociedade e, nesse caso, pode desenvolver a idéia da ação coletiva como a única maneira de obter informações desejáveis (13).

O sistema de norma regula a vida social e é desenvolvido, por um lado, como uma imposição externa, com uma participação mínima dos individuos e grupos e, por outro lado, como produto da interação no grupo e entre este e outras categorias sociais.

As crenças se constituem um fenômeno de ligação do indivíduo ao grupo $e$ isto significa que ambos se tomam realidades coletivas e individuais. Impossivel pensar em crença não compartilhada, não experienciada ao nivel de grupo, pelo menos em um sentido de representacôes coletivas

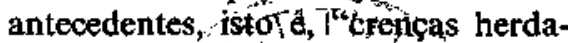
das" (3).
Movimentos soctals

Os movimentos sociais (MS) têm sido estudados na perspectiva de diversas ciências, como a Sociologia, a História e a Antropologia. Na Psicologia o estudo do tema é quase inexistente. Tajfel (12) revendo a literatura apontou para a escasez de estudos sob essa rubrica, à exceção dos trabalhos de Toch (14) e Toch e Milgran (15). Uma análise da literatura posterior à revisão desse autor, mostra que a situação pouco se alterou. Pode-se, no entanto, fazer menção ao trabalho de Reicher (9) que descreve uma rebeliâo (de St. Pauls) ocorrida em Bristol e a analisa em termos do modelo de identidade social da teoria do comportamento intergrupal.

Apesar de ter sido publicado há mais de duas décadas, o livro de Toch pode ser considerado como uma contribuição relevante no âmbito da Psicologia. $\mathrm{O}$ autor insere os movimentos sociais em uma classe mais ampla denominada de comportamento coletivo. Além de outros aspectos de interesse na área, como por exemplo, a questão da motivação, das crenças, etc., define movimentos sociais como um esforço na busca de mudanças na sociedade como um todo, ou de resistência a tentativas de mudanças.

Tajfel (12:46) aprofunda a discussão sobre 0 assunto definindo MS como "um esforço realizado por um grande número de pessoas que se definem e são freqüentemente definidos por outros como um grupo, para resolver coletivamente problemas que eles sentem terem em comum e que são percebidos como emergindo de suas relaçōes com outros grupos". Assim, os MS podem ser entendidos ao nível de análise como um grupo amplo, que desenvolve fronteiras demarcadas em relação a outros conjuntos sociais $\mathrm{e}$ propõe mudanças na estrutura social ou resiste a tentativas de mudancas.

\section{A quisa de conclusão}

No Brasil, embora se tenha observado uma proliferação de ações coletivas, a literatura psicológica parece não ter registrado nenhuma análise sobre o fenômeno. Alguns movimentos ganharam inclusive adesão nacional, como foi o caso do movimento contra a carestia (1978) e o movimento pela eleição presidencial ("Diretas, já"). Certas questões relacionadas à ação coletiva parecem exigir explicaçōes psicológico-sociais, como por exemplo, a motivação da filiação, a crença, a identidade individual-social, etc.

A base motivacional para a 
emergência dos MS tem sido relaciorada às contradições sociais, desenvolvendo-se, entào, uma tradição derivada dos estudos de Castells (1) e Lojkine (6) que tem marcado a produção no pais entre os movimentos sociais urbanos. Recentemente. a categoria "contradições sociais" vem sendo revista em termos de condição sufjciente ao aparecimento dos MS (5), apontando-se também para fatores culturais.

Questǒ̀es ainda em discussão na literatura sobre os MS parecem derivar da necessidade de intercämbio entre as áreas de estudo: Tal intercâmbio é defendido por autores de vertente antropológica (4) e sociológica (8). A Psicologia, como reconhece Melucci (7), poderia igualmente contribuir com o seu nivel de análise.

Defende-se, aqui, que o fenômeno do comportamento coletivo seja reassumido como objeto de estudo da Psicologia. Embora o quadro té́rico possa nẫo dar conta da complexidade inerente a esse objeto, a pesquisa empirica poderia suscitar necessidades de articulaçōes entre categorias derivadas de diferentes teorias psicológicas ou de outras áreas de conhecimento. A omissão da Psicologia aumenta a la- cuna sobre o tema em seu campo e a distancia daquelas ciências que vêm enfrentanto as questões colocadas pelo comportamento coletivo.
I. CASTELLS. M. Lutas urbanas e porter potitsco. Porlo. Grática Firmeza. 1976.

2. CARWRIGHT. D. e ZANDER, A. Dintimica do grupo. Sào Paulo, EPLI, 1975.

3. DUCHAC. R. Sociologia e Psicolegiat. Lisbod. Livraria Berirand. 1975.

4. DURHAM, E.R. Movimentos sociais: a cons Irução da cidadania. Novos Estudes $-C E$. BR.AP. 10: 24-30, 1984.

5. KOWARICK. L. Os caminhos do encontro: as lutas sociais em São Paulo na década de 70. Presensa. 2. 65.78, 1984

6. LOJKINE. J. O Estado capitadista a questato whana. Sảo Pauto, Marlins Fontes, 1981

7. MELUCCl, A. The new social movements: a theorelical approach Social Science Information - Sir les Sivences Sociates, 2, (19): 199-226. 1980.

8. NUNES, E. Carèncias urbanas e reivindicaçòes populares - Nolas. Ciências Soctiais, Hoje. 37.52. 1986

9. REICHER. S.D. The St. Pauls riot: an explanation of the limits of crowd action in terms of a social identity model. European Joturnol of Social Psychologs, 14: 1-21, 1984

10. SHERIF. M. A SHERIF, C.W. Groups in hamenty thd tersiont. New York, Harper (" l.1da. 1953

II. STEINER. I. D. Whatever hamened to the group in social psychology". Journat of Ever'imenral Sorial Pspchologi, 10, 94-108, 1974.

12. TAJFEL, H. Differentution bence's secist groups. New York Academic Ptess, 1978.

13. TAJFEL, H. Homom groups and soriat catte gories. New York Cambridge University Press. 198]

14. TOCH, H. The saciat prichologe of suciat morcments. Londres Melhuen \& C LTD, 1965

35. TOCH. H. e MILGRAN, S. Collective behaviour: crowds and social movements. I $h$ LINDZEY. G. and ARONSON. E. (eds) Hand thos' of Suriat Psychologr. Addison-Wesley, Reading. Mass Kiesler, C.A. 1969

16. TURNER, J.C. Social identification and psychological group formation. Em: TAJFEL. H. (ed). The social dimention. New York Cambridge University Press, 1984.

17. TURNER, J.C. e GIEES, H. InIroduction: the social psychology of intergroup behaviour. in: TURNER, J.G. e GILES, H. (eds). Inier. growp behaviour. Chicago, The Universily of Chicago Press, 1981

\section{Leitura}

\section{A loucura do trabalho.}

Júlia Abrah हैo

Instituto de Psicologia ltuiversidade de Brasilia.

Encontramos nesta obra de Cristophe DejoursA loucura do Trabalho, Oboré Editorial, 1987 - uma abordagem do trabalho até entảo pouco usual entre os profissionais da área de Psicologia Organizacional -o binômio organização do trabalho - saúde. $O$ axe central sobre o qual se construiu o livro traz em sua base o pressuposto que: "a organizaçào do trabalho exerce, sobre o homem, uma ação especifica, cujo impacto é o aparelho psiquico".

Através de pesquisas realizadas em diferentes setores da produção, Dejours ilustra de forma clara os diferentes mecanismos de defesa utilizados pelos trabalhadores. Esses mecanismos permitem sobreviver ao sofrimento imposto pela organizaçảo do trabalho vigente. Em outras situaçôes o autor demonstra como esse mes- mo sofrimento é recuperado pelas empresas em prol da produtividade.

É interessante ressaltar da análise do autor a identificação não só dos mecanismos de defesa ocupa. cional defensiva de caráter individual, mas também a ideologia ocupacional coletiva vigentes em determinadas áreas de produção. Ao resgatar a dimensão coletiva do sofrimento e as regras impostas pelo grupo para a execução das tarefas, Dejours nos remete diretamente a um questionamento da forma como o trabalho é organizado.

Crítico ferrenho do Taylorismo e seus múltiplos desdobramentos em matéria de organização do trabalho, o texto ilustra com exemplos oriundos do cotidiano do trabalho, aspectos tais como a insatisfação oriunda do conteúdo significativo e do conteúdo engonômico do trabalho.

$\mathrm{Na}$ relaçào do trabalhador com a organização do Trabalho, alem das estratégias defensivas, do so. frimento e da sua exploração, é interessante observar ainda a identificação do medo presente em diferentes situaçōes de trabalho; e esse medo se desdobra de forma diferenciada conforme a relação tarefa-organização do trabalho.

Resta como ponto fundamental da psicopatologia do trabalho a questão: a exploração do sofrimento pode ter repercussões sobre a saúde dos trabalhadores, do mesmo modo que podemos observar com a exploração da força física?

Contrariamente ao que parece sugerir o título da obra, não se pode provar uma patologia mental decorrente do trabalho. Uma das hipóteses do trabalho de Dejours coloca a organização do trabalho como causa de uma fragilização somáti- ca, na medida em que ela pode bloquear os esforços do trabalhador para adequar o modo operatório às necessidades de sua estrutura mental. Nós pensamos que por aí se abre um grande campo de investigação para a verificação dessas hi. póteses, com a vantagem de agrupar diferentes campos de atuação da psicologia, indispensáveis a um melhor conhecimento das relações homem-situação de trabatho.

O livro traz, em seu anexo, um modelo de metodologia em psicopatologia do trabalho, útil na operacionalização e bom guia no desenvolvimento de uma intervenção, deixando evidentemente um espaço para a adaptação à nossa realidade brasileira com peculiaridades diferentes da francesa.

A proposta que permeia todo o livro não é a de criar novos homens, mas encontrar soluçōes que permitiriam pôr fím à desestruturação de um certo número deles, pelo trabalho. 